\title{
Ueber die Fettresorption
}

\section{Yon}

\section{Dr. Med. S. Saito.}

Die Frage der Fettresorption ist ausserordentlich umfangreich und wichtig und viele Gelehrten haben sich schon mit der Lösung derselben beschäftigt. Früher waren viele Physiologen der Meinung, dass das Fett im Darmkanal in feinste Teilchen emulgiert und durch die Darmwand direkt in die Lymphgefässe gelangen kann. In neuerer Zeit kamen viele Forscher zu dem Resultat, dass das Fett schon vor der Resorption in seine Componenten : Fettsäuren und Glycerin sich spalte, dann erst resorbiert werde und nach der Resorption wieder Neutralfett bilde. Ob alles Fett vor der Resorption gespalten wird, ist eine noch ungelöste Frage. Wenn man die energische Fettspaltung im Darm und weiter den Umstand in Erwägung zieht, dass man bei Fütterung mit Fettsäure, Seife oder Fett von hohem. Schmelzpunkt doch. Neutralfett in den Lymphgefässen findet, kommt man zur Vermutung, das ein grosser Teil des Fettes in Dünndarm gespalten wird. Wie weit die Fettspaltung in Dünndarm geht, ist eines der wichtigsten Momente für die Fettresorption. Volhard (I) hat in neuerer Zeit betont, dass sich im Magensaft ein fettspaltendes Ferment finde, aber diese Beobachtung ist noch nicht bestätigt. Ich habe auf diesem Gebiete etwas geforscht. Ich will zuerst die Vorbereitung zu den Versuchen und die Versuchsreihen beschreiben und dann die daraus folgenden Schlüsse ziehen. 


\section{Yorbereitung zu den Yersuchen.}

Die Futtermischung für die Versuche wurde aus magerem Pferdefleisch, Oleinsäure und Schweinefett hergestellt. Ich habe die Olcïnsäure analysiert, den Säuregrad des Schweinefettes bestimmt und vor jeder Fütterung die Fettbestimmung des Pferdefleisches gemacht.

\section{Analyse der Oleinsäure.}

a.

2,2749 gr Oleinsäure wurden abgewogen und längere Zeit im Schwefelsäure-Exsiccator stehen gelassen. Nach der Herausnahme zeigte sich ein Gewichtsverlust von $0,0035 \mathrm{gr}=0,15 \%$ Wasser. Die Oleïnsäure

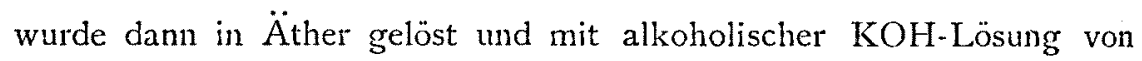
bestimmtem Gehalt titriert. Darnach wurde der Gehalt an reiner $\mathrm{C}_{18} \mathrm{H}_{i: 4} \mathrm{O}_{2}$ zu $97,79 \%$ gefunden.

Nach der untenstehenden Formel habe ich die Prozentzahl berechnet.

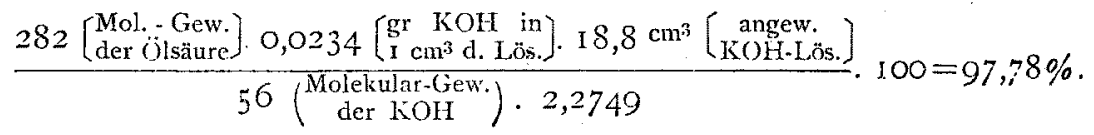

b.

Abgewogene Oleinsäure: $\quad 2,2346 \mathrm{gr}$

Gewichtsverlust nach der Trocknung: $0,005 \mathrm{gr}(0,22 \%$ Wasser $)$ Säuregrad durch Titrierung: $\quad 96,41 \%$.

Die angewandte Oleinsäure enthält also im Durchschnitt 97, 10\%.

\section{Bestimmung der freien Säure im Schweinefett.}

a.

21,6309 gr Schweinefitt wurden abgewogen und getrocknet; der Gewichtsverlust nach der Trocknung betrug 0,0410 gr (0,19\%).

Dann wurde esi in $\ddot{A}$ ther gelöst und mit alkoholischer KOH-Läsung titriert.

Darnach fand ich $0,76 \%$ freie Saüre (berechnet als Oleinsäure). 
b.

Abgewogenes Sehweinefett : $7,8239 \mathrm{gr}$

Gewichtsverlust nach der Trocknung: $0,0587 \mathrm{gr}$

Säuregrad durch Titrierung : $0,75 \%$.

Das angewandte Schiveinefett enthält also im Durchschnitt $0,75 \%$ freie Säure.

Herstellung der 10 prozentigen Fettsäure-Mischung.

Schweinefett und Oleinsäure wurden im Verhältnis wie 9: I abgewogen, geschmolzen und bis zur Gerinnung umgerührt.

\section{Säuregrad-Bestimmung der Mischung durch Titration.}

I. Fettsäuremischung (bei Versuch I, II, III).

1,0577 $\mathrm{gr}$ der Mischung würden abgewogen, in Äther gelöst und mit der $\mathrm{KOH}-\mathrm{L}$ ösung neutralisiert. Es wurden $0,9 \mathrm{~cm}^{3}$ verbraucht = $0,02 \%$ Oleïnsäure.

Nach bereits ausgeführter Berechnung enthalten: Io gr des verwendeten Präparates $9,7 \mathrm{gr} \mathrm{C}_{18} \mathrm{H}_{3: 4} \mathrm{O}_{2}$ 90 $\mathrm{gr}$ Schweinefett 0,6 gr freie Säure $100 \mathrm{gr}$ Fettsäuremischung I0,3 gr freie Säure als Oleinsäure berechnet.

II. Fettsäuremischung (bei Versuch IV, V und VI). $2,0636 \mathrm{gr}$ der Mischung wurden abgewogen und in Äther gelöst. Zur Neutralisation brauchte ich $1,825 \mathrm{~cm}^{3}$ der KOH-Lösung $=10,4 \mathrm{I} 3 \%$ Oleinsäure.

\section{Yersuchs-Anordnung.}

Jeder der 6 Hunde bekam mehrere Tage die bereits beschriebene Mischung. Eine bestimmte Zeit nach der letzten Fütterung wurde der Hund durch einen Schlag getötet und sofort die Banchwand eröffnet. Die Eingeweide wurden herausgenommen, der Magendarmtractus wurde an der Cardia, dem Pylorus, der Bauhinschen Klappe und mög̣lichst 
tief am Rectum doppelt unterbunden. Der Inhalt jedes Abschnittes wurde vorsichtig in das vorher gewogene Becherglas gesammelt und dessen Gewicht bestimmt. Jeder einzelne Inhalt wurde im Scheidetrichtes direkt mit $\ddot{A}$ ther geschüttelt und die Ätherschicht in einen. Kolben abgegossen; diese Manipulation wurde 5 mal wiederholt. Nachdem die ätherische Lösung mehrmals mit Wasser gewaschen war, wurde der

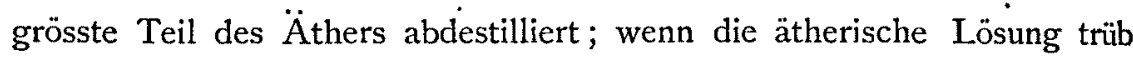
war, wurde sie filtriert. Die zuletzt erhaltene Lösung wurde in einem

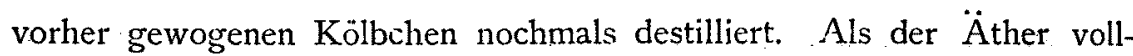
ständig abdestilliert war, habe ich durch das Kölbchen erwärmte trockene Luft geführt bis zur Gewichtskonstanz, weil ich beim Trocknen im Trockenschrank eine Zersetzung des Fettes befürchtete. Der erhaltene Ätherextrakt wurde in Äther gelöst und mit der KOH-Lösung titriert. Aus der angewandten Menge der Kalilauge habe ich deniSäuregrad als Oleinsäure berechnet. Die Dünndarm- und Mastdarm-Inhalte habe ich weiter mit $\mathrm{H}_{2} \mathrm{SO}_{4}$ angesäuert, abermals mit Äther geschüttelt und die oben beschriebene Manipulation wiederholt.

Die Dünndarmwand habe ich sorgfältig präpariert um subperitonẹales Fettgewebe wegnehmen zu können, dann den Darm eröffnet und den Inhalt sorgfältig mit Fliesspapier abgewischt. Hierauf wurde diese Darmwand gewogen und die Fettbestimmung derselben vorgenommen.

\section{Versuch I.}

Hund, 2,25 kg schwer, musste 24 Stunden hungern; am 7. März um $12^{\mathrm{h}}$ bekam er eine Mischung von $\mathrm{I} 50 \mathrm{gr}$ Fleisch $(3,93 \%$ Fett $)$ und $30 \mathrm{gr}$ der Io \% igen Fettmischung.

Am 8. März um Io hekam ber Hund dasselbe Futter, dessen Fleisch I,93\% Fett enthielt. Am 9. März um Io erhielt er das gleiche Futter (Fettgehalt $4,98 \%$ ). Um $4^{\mathrm{h}}$ wurde er getötet.

Magen-Inhalt: 3 I gr; Inhalt gleichmässig gemischt, dickbreiig, mit geringem Säuregeruch; reagierte stark sauer.

Dünndarm-Inhalt $=19 \mathrm{gr}$. Er war gallertartig, im oberen $\mathrm{i}$ Teil weiss, im mittleren gelblichgrün, im unteren grünlichschwarz gefärbt, 
enthielt keine sichtbaren Fleischstückchen und hatte keinen besonderen Geruch.

Mastdarm-Inhalt $=5 . \mathrm{gr}$; derselbe , war ebenfalls dickbreiig und schwarz gefärbt und hatte kotähnlichen Geruch.

Ätherextrakt aus Dünndarm-Inhalt betrug $0,7297 \mathrm{gr}$.

$\ddot{A}$ therextrakt aus Mastdarm-Inhalt $=0,257^{8} \mathrm{gr}$.

\section{Versuch II.}

Körpergewicht des Hundes 3,02 kg.

Hungerzeit : 36 stunden.

Io. März I $2^{\mathrm{h}}$ I 50 gr Fleisch von $4,98 \%$ Fettgeh. u. 30 gr Fettmisch.

II. " $12^{\text {h }}$ I $50 \mathrm{gr}, ", 5,9 \%, ", 30 \mathrm{gr}$,

12. " $10^{\mathrm{h}} 200 \mathrm{gr}, \quad$, $1,5 \%$ " " $40 \mathrm{gr}$,

13. " 12 h $200 \mathrm{gr}, \quad, \quad \mathrm{I}, 5 \%, \quad, 40 \mathrm{gr}$,

I4. , $\mathrm{I}^{\mathrm{h}} 200 \mathrm{gr}, \quad, 2,5 \%, \quad, 40 \mathrm{gr}$,

14. ” $5^{\text {h }}$ getötet.

Inhalt des Magens I64 gr, des oberen Dünndarm-Abschnittes $22 \mathrm{gr}$, des unteren I I gr, des Mastdarmes $5 \mathrm{~g}$.

Sämtliche Inhalte hatten dieselbe physikalische Beschaffenheit wie bei Versuch I.

\section{Versuch III.}

Körpergewicht des Hundes 2,49 kg.

Hungerzeit 24 Stunden.

I5. März $12^{\mathrm{h}} 200 \mathrm{gr}$ Eleisch von $3,3 \%$ Fettgeh. u. $40 \mathrm{gr}$ Fettmisch. 16. , $12^{\mathrm{h}} 200 \mathrm{gr}, \quad, \quad 0,8 \%, " \quad 40 \mathrm{gr}$,

I7. " 12 h I $50 \mathrm{gr}, \quad, 4,4 \%, \quad, \quad 30 \mathrm{gr}$,

I8. , , gehungert.

I9. ,. $2^{\text {h }}$ 150 gr,$"$,, $9 \%$ " $30 \mathrm{gr}$,

20. " 12 h 150 gr $, \quad, \quad 0,9 \%, ", 30 \mathrm{gr}$,

2I. " gehungert.

22. " IO ${ }^{\mathrm{I}} \mathrm{I} 5 \mathrm{O}$ gr $, " 5,3 \%, " 30 \mathrm{gr}$,

Ex 'frass nur $2 / 3$ der Futtermenge und musste deshalb bis 24 . März hungern. 
24. ", $\quad 7^{\text {h }}$ I 50 gr Fleisch von 1,24\% Fettgeh. u. 30 gr Fettmisch. 24. ", 1 he getötet.

Inhalt des Magens I $30 \mathrm{gr}$, des oberen Dünndarm-Abschnittes $18 \mathrm{gr}$, des unteren $8 \mathrm{gr}$, des Mastdarmes $13 \mathrm{gr}$.

Die Beschaffenheit aller Inhalte war gleich wie bei Versuch I.

\section{Versuch IV.}

Körpergewicht des Hundes $5,66 \mathrm{~kg}$.

Hungerzeit 24 Stunden.

29. März to h $150 \mathrm{gr}$ Fleisch von $3,4 \%$ Fettgeh. u. $30 \mathrm{gr}$ Fettmisch. 30. " $4^{\text {h }} 150 \mathrm{gr}$ " " $3,4 \%$ " " $30 \mathrm{gr}$ ", $3 \mathrm{I}$. " $10^{\mathrm{h}} \mathrm{I} 5 \mathrm{O} \mathrm{gr}, ", 2,4 \%$ " , $30 \mathrm{gr}$,

I. April roh $150 \mathrm{gr}, \quad$ " $2.9 \%$ " " $30 \mathrm{gr}$ ","

2. " IO h I $50 \mathrm{gr}, "$ " $5,4 \%$ " $30 \mathrm{gr}$,

3. "IOhI $50 \mathrm{gr}, "$, $4, \mathrm{I} \%$, , $30 \mathrm{gr}$,

3. " $5^{\text {h }}$ getötet.

Inhalt des Magens $95 \mathrm{gr}$, des oberen Dünndarm-Abschnittes $32 \mathrm{gr}$, des unteren $9 \mathrm{gr}$, des Mastdarmes $3 \mathrm{gr}$.

Die Inhalte zeigten gleiche Bachaffenheit wie bei Versuch I.

\section{Versuch V.}

Köpergewicht des Hundes $2,19 \mathrm{~kg}$.

Hungerzeit 24 Stunden.

4. April $12^{\text {h }}$ 150 gr Fleisch von 2,2\% Fettgeh. u. $30 \mathrm{gr}$ Fettmisch.

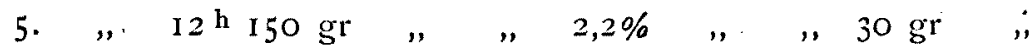

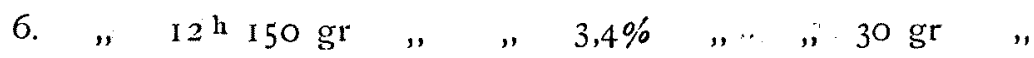

7. " $2_{2}$ h $150 \mathrm{gr}$, " $3,6 \%$ " " $30 \mathrm{gr} .$,

8. " IO h $150 \mathrm{gr}, \quad, 3,6 \%, \quad, 30 \mathrm{gr}$,

8. " $4^{\mathrm{h}}$ getötet.

Inhalt des Magens I $31 \mathrm{gr}$, der oberen Hälfte des Dünndarmes I4 gr, der unteren Hälfte $8 \mathrm{gr}$, des Mastdarmes $5 \mathrm{gr}$.

Dei Dünndarm-Inhalt war etwas flüssig, die übrigen Inhalte waren von gleicher Beschaffenheit wie bei Versuch I. 


\section{Versuch VI.}

Körpergewicht des Hundes $1,55 \mathrm{~kg}$.

Hungerzeit 24 Stunden.

10. April Io h $^{\text {h } 50} \mathrm{gr}$ Fleisch von $3,3 \%$ Fettgeh. u. $30 \mathrm{gr}$ Fettmisch.

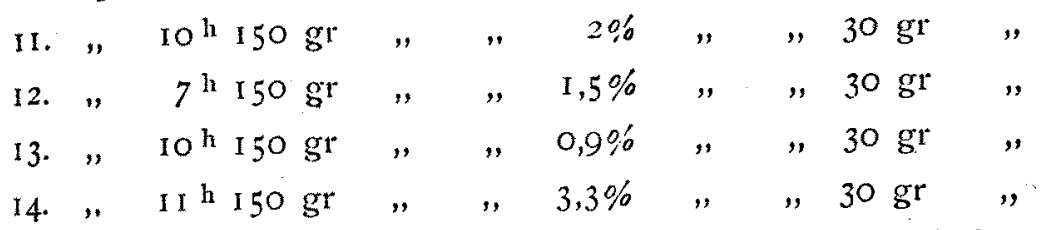

Der Hund frass nur $128 \mathrm{gr}$ Flcisch und $25 \mathrm{gr}$ Fettmischung.

14. April $5^{\text {h }}$ getötet.

Der Magen-Inhalt betrug $9 \mathrm{r}$ gr. Der Inhalt des oberen DünndarmAbschnittes betrug $23 \mathrm{gr}$, die Menge des unteren Dünndarm-Abschnittes I $5 \mathrm{gr}$, jene des Mastdarmes $5 \mathrm{gr}$.

In Dünndarm waren viele Würmer; die Wand war stark gerötet. In Magen und Mastdarm waren auch einige Würmer, aber ich konnte kein Zeichen von Entzündung wahrnehmen. Die Beschaffenheit eines jeden Inhaltes war nicht anders wie bei den anderen Versuchen.

Zur besseren Übersicht stelle ich die Daten dicser Untersuchungen tabellarisch zusammen. 


\begin{tabular}{|c|c|c|c|c|c|c|c|c|c|}
\hline \multirow{2}{*}{ 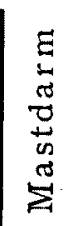 } & 20 & \multirow{2}{*}{ 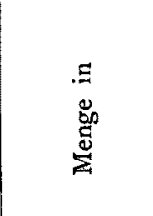 } & \multirow[t]{2}{*}{29} & है & $\begin{array}{l}8 \\
\text { i }\end{array}$ & ผू & $\begin{array}{l}\stackrel{8}{8} \\
0 \\
0\end{array}$ & \begin{tabular}{l|l}
0 & $\infty$ \\
$\infty$ & $\infty$ \\
$\infty$ & 0
\end{tabular} & $m \mid=$ \\
\hline & \pm & & & in & $\cong$ & $: m$ & in & $\cdot \operatorname{men}$ & $n$ \\
\hline \multirow{4}{*}{ 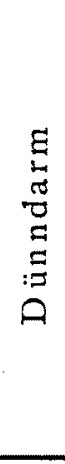 } & $\stackrel{m}{m}$ & \multicolumn{2}{|c|}{ 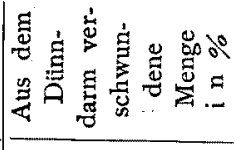 } & 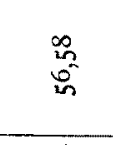 & $\underset{8}{8}$ & $\stackrel{\infty}{\stackrel{\infty}{*}}$ & $\underset{2 n}{=}$ & 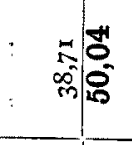 & $\begin{array}{l}\text { Na } \\
\text { s. } \\
\text { s. }\end{array}$ \\
\hline & N & 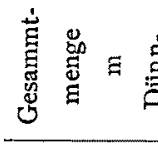 & $\frac{\Xi}{8}$ & $m$ & \&. & $F$ & N & 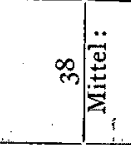 & 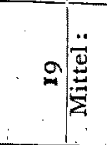 \\
\hline & \pm & \multicolumn{2}{|c|}{ 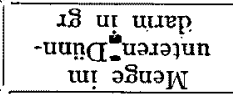 } & $\stackrel{\mathrm{H}}{\mathrm{m}}$ & $\infty$ & o & $\infty$ & 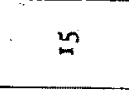 & 1 \\
\hline & 욕 & \multicolumn{2}{|c|}{$\begin{array}{c}\text { I8 u! uxiep } \\
\text {-uuṇ uəsəq) } \\
\text { u! əsuวW } \\
\end{array}$} & ते & $\stackrel{\infty}{\sim}$ & लै. & \pm & $\stackrel{m}{M}$ & 1 \\
\hline \multirow{5}{*}{$\begin{array}{l}E \\
0 \\
\infty \\
\infty \\
\pm\end{array}$} & $a$ & \multirow{3}{*}{ 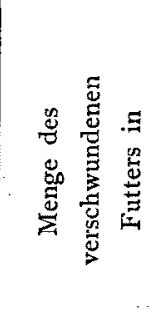 } & $\stackrel{1}{2}$ & $\mathfrak{m}^{2}$ & $\ddot{6}$ & s... & 寗 & 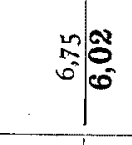 & $\begin{array}{l}9 \\
\text { ñ }\end{array}$ \\
\hline & $\infty$ & & 29 & $\underset{\hat{\sigma}}{\hat{n}}$ & $\frac{\infty}{N}$ & $\begin{array}{l}\hat{y} \\
\hat{y}\end{array}$ & 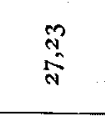 & $\because \underset{n}{m}$ & 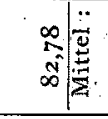 \\
\hline & $N$ & & $\infty$ & $\stackrel{0}{1}$ & 은 & 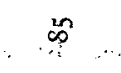 & 웋 & है & $\stackrel{9}{7}$ \\
\hline & 0 & \multirow{2}{*}{ 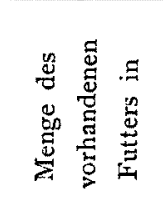 } & 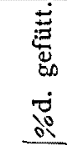 & $\begin{array}{l}3 \\
3 \\
0\end{array}$ & $\begin{array}{c}\text { N } \\
\text { N } \\
N\end{array}$ & in & $\frac{n}{n}$ & $\begin{array}{l}\text { F } \\
\text { in }\end{array}$ & $\underset{N}{N}$ \\
\hline & in & & bo & $\stackrel{+}{+}$ & 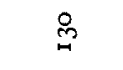 & 2 & $\ddot{m}$ & $\sigma$ & m \\
\hline & + & \multicolumn{2}{|l|}{ 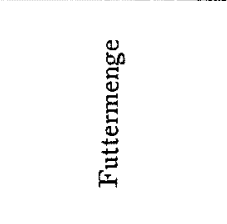 } & 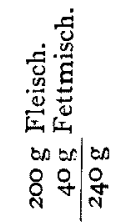 & 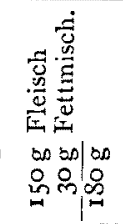 & 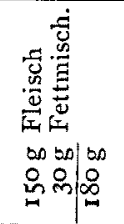 & 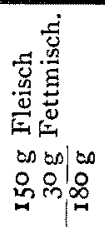 & 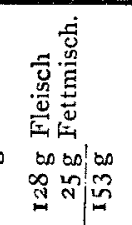 & 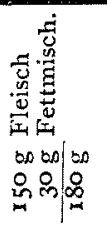 \\
\hline & $m$ & \multicolumn{2}{|c|}{ 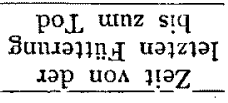 } & $2 n$ & 0 & $\omega$ & 0 & 0 & 0 \\
\hline & $N$ & \multicolumn{2}{|c|}{ 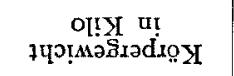 } & m & $\hat{n}$ & F & ส̃ & $\stackrel{0}{-1}$ & N \\
\hline & - & чวusxə $\Lambda$ & & $\Xi$ & $\Xi$ & $Z$ & $>$ & $B$ & $\mapsto$ \\
\hline
\end{tabular}


Bei Betrachtung "dieser Tabelle fällt es auf, dass nach 6 Stunden im Magen eine ziemlich grosse Menge - $9 \mathrm{I}$ bis I $64 \mathrm{gr}$ - (ausser bei Versuch I) vorhanden ist und dass bei mässiger Fütterung kleinerer Hunde $6 \%$ (siehe Rubrik 9)des Futters pro Stunde aus dem Magen in den Dünndarm übertreten und $50,04 \%$ (Rubrik I 3 ) der in den Dünndarm übergetretenen Futtermischung - abgesehen von einer geringen Menge, die eventuell in den Mastdarm übergegangen ist - von der Dünndarm-Wand resorbiert wurden.

Bei Versuch I ist eine ungefähr doppelt so grosse Menge aus dem Magen in den Dünndarm übergegangen $(82,7, \% \%)$ und die von der Dünndarm-Wand resorbierte Menge betrug $87,27 \%$. Was der Grund der schnelleren Bewegung in diesem Falle war, kann ich nicht ermitteln, keinesfalls können Körpergewicht und Hungerzustand in Betracht kommen.

Wenn ich aus den 6 Versuchen die Durchschnittszahl ziehe, finde ich, dass 9,9\% des Futters pro Stunde aus dem Magen in den Dünndarm übergingen und $68,66 \%$ von der Dünndarm-Wand resorbiert wurden. Von allen Inhalten wurden nach vorbeschriebener Methode Fettgehalt und Säuregrad bestimmt. Ich ordne die Resultate zur besseren Übersicht tabellarisch. (II. u. III.)

Nachstehende Tabelle zeigt, dass 6 Stunden nach der Fütterung die Fettmenge im Magen 50,44\% betrug und dass $8,39 \%$ Fettmischung pro Stunde aus dem Magen in den Dünndarm übergegangen sind.

Frank (2) hat in seinen Versuchen nachgewiesen, dass im allge meinen $4,3 \%$ der verfütterten Fettsäure (ca. $50 \mathrm{gr}$ ) pro Stunde aus dem Magen in den Dünndarm übertreten bei Hunden mittlerer Grösse. Die von mir gefundene \%-Zahl beträgt beinahe das Doppelte. Als Grund dafür kann ich nur den Umstand ansehen, dass meine Versuchstiere ganz jung waren und die dem Futter zugesetzte Fettmischung gering war. Ferner ersieht man aus Tabelle II, dass $93,5 \%$ (das Mittel aus Versuch III, IV, V) der in den Dünndarm übergegangenen Futtermischung von der Dünndarm-Wand resorbiert wurden, abgesehen von der geringen Menge, die sich vorher im Dünndarm befand und von derjenigen, welche in den Mastdarm gelangt war. 


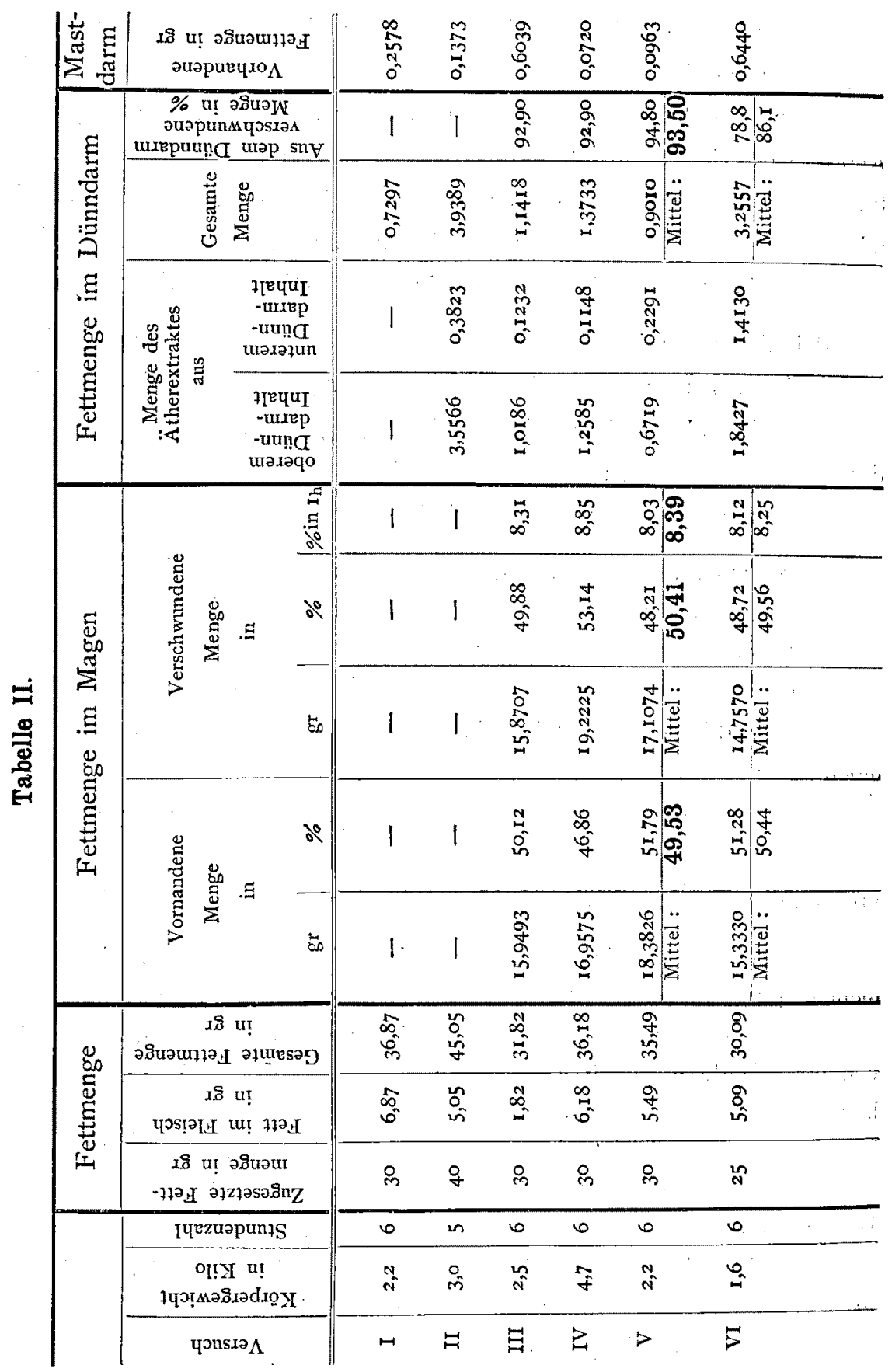


M unk (3) hat festgestellt, Fr. Müller (4) und Arnschink (5) haben bestätigt, dass Olivenöl zu 97,7\%, Gänse- und Schweinefett zu $97,5 \%$ resorbiert werden; die von mir gefundene \%-Zahl $(93,5)$ kommt der eben erwähnten sehr nahe.

Versuch VI konnte jch nicht zur Durchschnittsberechnung aufnehmen, weil der Hund krank war (Versuch VI!). Die entzündete Darmwand verminderte die Resorptionsfähigkeit in hohem Grad ; die Resorptionsmenge betrug nur 78,8\%. Wenn ich auch diesen Versuch bei Berechnung der Durchschnittszahl in Betracht ziehe, beträgt die resorbierte Menge $86,10 \%$.

Die älteren Physiologen waren der Ansicht, dass Fette im Magen keine Veränderung erleiden; Marpmann (6) jedoch hat nach längerem. Schütteln des Fettes mit künstlichem Magensaft stets das Vorhandensein freier Fettsäure und einer Spur Glyzerin nachweisen können.

Der erste, der eine hydrolytische Spaltung des Neutralfettes im Magen nachgewiesen hat, war Marcet (7). Er fütterte Hunde mit fettreichem Fleisch und beobachtete, als er den Magen-Inhalt $1-5$ Stunden nach der Fütterung untersuchte, stets das Vorhandensein freier Fettsäure.

Die Richtigkeit der Angabe, dass der Magen auch aus neutralen Fetten Fettsäure abspalten kann, wurde von vielen Autoren: Cash (8), Ogata (9), Klemperer und Scheurlen (ro) und Fr. Müller (II) an Hunden und Menschen erforscht. Den Resultaten nach ist die Menge der abgespaltenen Fettsäure nur $\mathrm{I}-2,7 \%$ nach einigen Stunden ; nur bei hochgradiger Stenose des Pylorus wurden etwas höhere Zahlen $(4,9-6 \%)$ gefunden.

Nach der Beobachtung Volhard's reagierte eine Eigelb-Emulsion, welche er in den Magen von Menschen einführte und nach einiger Zeit wieder auspumpte, stark sauer. Quantitative Bestimmungen zeigten, dass innerhalb eines $\mathrm{I}-4$ stündigen Aufenthaltes im Magen die Spaltung auf $78,8 \%$ anstieg. Nach diesem Autor und seinem Schüler Stade (12) vermag das Ferment nur auf künstlich oder natürlich emulgierte Fette zu 
wirken. Da die Gegenwart von Säure bekanntlich die Emulsion beeinträchtigt und das Enzym durch Pepsin und $\mathrm{HCl}$ verdaut und zerstört wird, sit ein hyperacider Magensaft weit weniger wirksam gegenüber dem Fett als in säureärmerer. Diese Beobachtung ist jedoch nicht einwandfrei.

Vor einiger Zeit hat In o uye (13) im pharmakologischen Institut zu Würzburg diese Frage genauer studiert. Er hat verschiedene Verdauungsgemische gemacht aus Mandelöl, Olivenöl (beide sowohl emulgiert als auch nicht emulgiert), Eigelblösung, Milch, Glyzerinextrakt aus den verschiedenen Abschnitten der Schweinemagen-Schleimhaut, we!cher bei einigen Versuchen nach dem Kochen benutat wurde und Pawlow:schem Magensaft. Mit diesen Gemischen suchte er die Verdauungsverhältnisse $z \mathfrak{u}$ erforschen und seine Resultate führten $\mathrm{zu}$ dem Schluss, dass sich die fettspaltende Wirkung des Magensaftes und Glyzerinextraktesder Fundusschleimhaut nicht bestätigt. Das Resultat der Versuche' welche Herr Prof. K unkel (14) ausgeführt hat, steht auch im Gegensatz zu Volhard's Beobachtung. Herr Prof. Kunkel fand, dass sich der Gehalt des im Magen stundenlang verweilten Fettes an, freier Fettsäure nur um wenige Prozente vermehrte $(\mathrm{I}-2 \%)$. Inouye hat auch an Katzen 3 Versuche gemacht und fand, dass bei $12-24$ stündigem Verweilen die Fettsäure durch die Magenverdauung etwa um $1 \%$ zunehmè. Meine Resultate bestätigen die Befunde von Inouye und Herrn Prof. Kunkel.

\section{Tabelle III.}

Ma ge n.

\begin{tabular}{|c|c|c|c|c|c|}
\hline $\begin{array}{l}\stackrel{5}{0} \\
\stackrel{0}{0} \\
\stackrel{0}{0}\end{array}$ & $\begin{array}{l}\text { Menge der im } \\
\text { Magen vor- } \\
\text { handenen } \\
\text { Futtermenge }\end{array}$ & $\begin{array}{l}\text { Menge des } \\
\text { Äther- } \\
\text { extraktes }\end{array}$ & $\begin{array}{l}\text { Freie Fett- } \\
\text { sänre als } \\
\text { Oleînsäure } \\
\text { in } \%\end{array}$ & $\begin{array}{l}\text { Weisse } \\
\text { Substanz }\end{array}$ & Anmerkung \\
\hline I & $3 \mathrm{gr}$ & 一 & - & - & $\begin{array}{l}\text { Aus der atherischen } \\
\text { Lösung scheidet sich so- }\end{array}$ \\
\hline II & $164 \mathrm{gr}$ & - & - & - & $\begin{array}{l}\text { fort beim Eindampfen } \\
\text { diese weisse Substanz } \\
\text { Durch Analyse der }\end{array}$ \\
\hline III & I3o $\mathrm{gr}$ & & I 2,44 & & $\begin{array}{l}\text { Substanz konnte ich } \\
\text { nachweisen, dass dieselbe }\end{array}$ \\
\hline IV & $95 \mathrm{gr}$ & $\mathrm{I6,9575 \textrm {gr }}$ & I I, 68 & $0,486 \mathrm{rgr}$ & $\begin{array}{l}\text { ein Neutralfett ist, des- } \\
\text { halb muss die Prozent- }\end{array}$ \\
\hline V & $131 \mathrm{gr}$ & $18,3826 \mathrm{gr}$ & 12,65 & $0,5910 \mathrm{gr}$ & zahl der freien Säure des \\
\hline VI & $9 \mathrm{rgr}$ & I5,3330 gr & I 2,42 & $0,4856 \mathrm{gr}$ & $\begin{array}{l}\text { Ätherextraktes etwas ge- } \\
\text { ringer sein,was aus Tabelle } \\
\text { IV ersichtlich ist. }\end{array}$ \\
\hline
\end{tabular}


Ich fand, wie, vorstehende Tabelle zeigt, nur eine ungefähr I-2\% ige Zunahme freier Fettsäure nach dem 6 stündigen Aufenthalt des Neutralfettes im Magen.

Hier ist vielleicht auch der Ort von der bei der Extralition der Fettmischung aus dem Mageninhalt erhaltenen weissen Substanz zu sprechen. Die zur Verfügung stehende Menge war so gering, dass die Natur derselben nicht definitiv festgestellt werden konnte. Sie ist in Äther schwer, in Alkohol noch schwerer, in Wasser gar nicht löslich und krystallinisch. Die Menge derselben war 0,5 gi. im Durchschnitt.

Die Substanz hatte einen Schmelzpunkt von $65-66^{\circ} \mathrm{C}$. Sie enthielt keine Asche, keinen $\mathrm{N}$, keinen $\mathrm{P}$ und keinen $\mathrm{S}$. Die warme ätherische Lösung reagierte ganz neutral, ist also keine freie Fettsäure. Nach den angestellten Versuchen ist die Substanz wahrscheinlich ein Neutralfett.

Ich habe die Substanz mit Barytwasser verseift (die Verseifung ging sehr langsam) und filtriert. Dem Filtrat habe ich sorgfältig $\mathrm{H}_{2} \mathrm{SO}_{4} \mathrm{zu}$ gesetzt, um Baryt auszufällen, dann das Filtrat auf dem Wasserbad bis auf einige $\mathrm{cm}^{3}$ eingedampft und damit einige Reaktionen auf Glyzerin Gemacht.

I. Die Lösung löste ein wenig Kupfer.

2. Bei Verbrennung roch sie nach Akrolein.

Die aus der Seife frei gemachte Fettsäure wurde auf dem Filterpapier gesammelt und getrocknet. Diese schneeweisse freie Säure war in Äther nicht schwer löslich, reagierte sauer und hatte einen Schmelzpunkt von $55-58^{\circ} \mathrm{C}$.

Ein e damit angestellte Elementaranalyse (die Substanz war zu Ende) machte wahrscheinlich, dass Tripalmitin vorliegt.

Weil die weisse Substanz ein Neutralfett ist, muss man die Menge derselben der Menge des Ätherextraktes aus dem Mageninhalt zufügen und dann die Prozentzahl der frejen Fettsäure berechnen. Nach dieser 
Berechnung stelle ich folgende Tabelle auf.

(Die Prozentzahlen in der Tabelle III sind o h ne Berücksichtigung der weissen Substanz berechnet, deshalb sind sie etwas niedriger anzunehmen.)

\section{Tabelle IV.}

Magen.

\begin{tabular}{|c|c|c|c|c|c|c|c|}
\hline I & 2 & 3 & 4 & 5 & 6 & 7 & 8 \\
\hline Versuch & 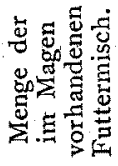 & $\begin{array}{l}\text { Menge } \\
\text { des } \\
\text { Äther- } \\
\text { extraktes }\end{array}$ & $\begin{array}{c}\text { Menge } \\
\text { der } \\
\text { weissen } \\
\text { Substanz }\end{array}$ & $\begin{array}{l}\text { Gesamt- } \\
\text { menge } \\
\text { aus } \\
3 \text { und } 4\end{array}$ & $\begin{array}{l}\text { Freie } \\
\text { Fettsäure } \\
\text { als Oleïn- } \\
\text { säure } \\
\text { in } \%\end{array}$ & $\begin{array}{c}\text { Säuregrad } \\
\text { der } \\
\text { Fett- } \\
\text { mischung } \\
\text { in } \%\end{array}$ & 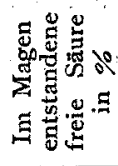 \\
\hline I & $3 \mathrm{gr}$ & - & 一 & - & - & - & - \\
\hline II & $164 \mathrm{gr}$ & - & - & - & - & - & - \\
\hline III & $130 \mathrm{gr}$ & $15,9493 \mathrm{gr}$ & $0,4 \mathrm{I} I 6 \mathrm{gr}$ & $16,3609 \mathrm{gr}$ & 12,13 & 10,02 & $2, \mathbf{I I}$ \\
\hline IV & $95 \mathrm{gr}$ & $\mathrm{r} 6,9575 \mathrm{gr}$ & $0,486 \mathrm{rgr}$ & $17,4436 \mathrm{gr}$ & I I, 35 & 10,41 & 0,94 \\
\hline V & $131 \mathrm{gr}$ & $18,3826 \mathrm{gr}$ & $0,5910 \mathrm{gr}$ & $18,9736 \mathrm{gr}$ & 12,26 & $10, \mathbf{4}^{1}$ & $\mathrm{I}, 85$ \\
\hline VI & $9 \mathrm{rgr}$ & $15,333^{\circ} \mathrm{gr}$ & $0,4856 \mathrm{gr}$ & $\mathrm{I} 5,8 \mathrm{r} 86 \mathrm{gr}$ & 12,04 & 10,41 & $x, 63$ \\
\hline & & & & & & Mittel : & 1,63 \\
\hline
\end{tabular}

$\mathrm{Ob}$ diese geringe Prozentzahl von 0,94-2, I I der gespaltenen Fettsäure durch die Wirkung des Fermentes im Magensaft hervorgerufen worden ist oder durch die Wirkung der Bakterien wie Bunge (15) und Munk ( I6) sagen oder durch die hydrolytische Spaltung unter Einfluss von Wasser und Wärme oder durch den abschwächenden Einflușs des hohen Säuregrades des Magensaftes oder durch die eigene schwache Spaltungskraft des Fermentes, wie Bengen ( I 7 ) und $\mathrm{Ha}$ a ne ( I 7 ) sagen, kann ich nicht erklären.

Kurz, nach meinen Resultaten kann ich nicht glauben, dass im Magen jene lebhafte Fettspaltung stattfindet, wovon einige Autoren sprechen.

Die im hiesigen Institut angestellten Versuche haben gleichmässig das Ergebnis geliefert, dass die durch einige Stunden im Magen verweilten Fettmengen um $\mathrm{I}-2 \%$ Fettsäure mehr enthielten als die anfänglichen Gemische. 
Es sollte nun geprüft werden, ob diese Spaltung vielleicht schon durch die Gegenwart von $\mathrm{HCl}$ erklärbar sei. Es wurde deshalb die Wirkung von $\mathrm{HCl}$ auf verschiedene Fettmischungen geprüft.

Zuerst habe ich eine Fettsäuremischung, welche nach der

\section{Titrierung $4,72 \%$, nach der}

II. Titrierung 4,8I \%, im Durchschnitt also

4,76\% freie Fettsäure enthielt, hergestellt.

\section{Versuch.}

Wirkung der $\mathrm{HCl}$ auf Fett.

I. Mischung: 2,134I gr Fettsäuremischung,

$5 \mathrm{~cm}^{3}$ physiol. $\mathrm{NaCl}$-Lösung mit

2 gr Gummi arab. emulgiert, $10 \mathrm{~cm}^{3}$ der $0,575 \%$ HCl-Lösung.

Nach 5 Stunden im Brutofen mit Äther geschüttelt; äther. Lösung mit Wasser gewaschen und mit alkoh. KOH-Lösung titriert.

Säuregrad: $4,76 \%$.

II. Mischung: 1,5425 gr Fettsäuremischung,

$5 \mathrm{~cm}^{3}$ physiol. NaCl-Lösung mit

2 gr Gummi arab. emulgiert,

10 $\mathrm{cm}^{3}$ der $0,575 \% \mathrm{HCl}$-Lösung.

Nach $21 \frac{1}{2}$ Stunden im Brutofen ganz genau wie oben behandelt.

Säuregrad : $4.72 \%$.

\section{Versuch.}

Wirkung a uf Eidotrer.

Eidotter enthält 0,63 bis 0,76 bis $0,85 \%$, also durchschnittlich $0,74 \%$ freie Säure.

I. Mischung: 4,3753 gr Eidotter,

$15 \mathrm{~cm}^{3}$ der $0,575 \%$ HCl-Lösung. 
Nach $23^{\mathrm{h}} 30^{\prime}$ im Brutofen wie oben behandelt.

Säuregrad : $2,3 \%$ ( I,56\% Zunahme).

II. Mischung: $3,4358 \mathrm{gr}$ Eigelb,

I $5 \mathrm{~cm}^{3}$ der $0,575 \% \mathrm{HCl}$-Lösung.

Nach $14^{\text {h }} 30^{\prime}$ im Brutofen wie oben behandelt.

Säuregrad : $2,16 \%(1,42 \%$ Zunahne $)$.

III. Mischung: 4,692 I gr Eigelb (0,63\% freie Säure), I $5 \mathrm{~cm}^{3}$ der $0,575 \%$ HCl-Lösung.

Nach $22^{\mathrm{h}} 3 \mathrm{O}^{\prime}$ im Brutofen wie oben behandelt.

Säuregrad: $3,32 \%(2,69 \%$ Zunahme $)$.

IV. Mischung: 5,I760 gr Eigelb (0,76\% freie Säure),

I $5 \mathrm{~cm}^{3}$ destilliertes Wasser,

Nach $17^{\mathrm{h}} 3 \mathrm{O}^{\prime}$ im Brutofen wie oben behandelt.

Säuregrad : $0,65 \%$.

Nach den Resultaten meiner Versuche spaltet $0,575 \% \mathrm{HCl}$ Fettmischung nicht, wohl aber Eidotter. Im letzten Falle war nach $22^{1 / 2}$ Stunden eine Zunahme von $2,69 \% \mathrm{zu}$-verzeichnen.

Ich muss hier kurz die Einwirkung von Schimmelpilzen, Hefen und Bakterien auf Fette erwähnen. Dass Bakterien Fette und andere Glyzerinester zerlegen können, kann als sichergestellt gelten. Camus (I8) und Gérard(I9) haben nachgewiesen, dass Penicillium und Aspergillus Monobutyrin zerlegen. Laxa (20) zeigte, dass die letztgenannten Schimmelpilze und in noch höherem Grade die Mukorarten auch wirkliche Fette zu zerlegen vermögen. Wenn man diese Pilzarten verreibt und filtriert, so erhält man einen sehr stark auf die Fettspaltung wirkenden Saft. Biffen (2I) fand, dass eigentümliche, auf Kokosfrüchten wachsende Sprosspilze Kokosfett und Monobutyrin spalten und ein in Wasser lósliches, durch Alkohol fällbares, fettspaltendes Enzym enthalten. 
mi: Weiter wurde diese Aufgabe von Gelẹhrten wie: $\mathrm{i}$ Kr üger und Schreiber (22), Rubner (23), E. v. Sommaruga (24) erforscht. Der letztere hat betont, dass Spirillum Cholera, Typhus und viele andere pathogene Keime eine fettspaltene Kraft haben,

Escherich (25) isolierte aus dem Darm von Säuglingen folgende, teilweise recht stark fettspaltende Bakterien :

Bacillus subtilis spaltete Milchfett bis zu 31,19\%,

Streptococcus gracilis bis $\mathrm{zu} 8,8 \%$,

Bact. lactis aërogenes bis $\mathrm{zu} 34,24 \%$,

Bact. coli aërogenes bis zu $62,7 \%$.

Die einwirkung des Pankreassaftes auf Fette wurde von vielen Gelehrten untersucht und wie folgt gefunden:

8 Tropfen Sekret aus einer Pankreascyste haben aus 0,9 gr Neutralfett in 4 Stunden bei $40^{\circ} \mathrm{C}=0,1299 \mathrm{gr}$ freie Fettsäure abgespalten. [Herter (26)].

$6 \mathrm{~cm}^{3}$ derselben gegen $3 \mathrm{gr}$ Hammelfett in 24 Stunden bei $38^{\circ} \mathrm{C}$ haben 0,1233 gr freie Fettsäure abgespalten. (Herter).

Nach Lüdy (27) hat Schweine-Pankreas aus Milch + verdünnte Soda-Lösung $86,4 \%$ Fettsäure abgespalten.

Wassilieff (28) fand, dass I67 gr wässeriger oder Glyzerin-Extrakt gegen 5 grm Butter in 22 Stunden 0,235 gr freie Fettsäure abgespalten haben.

Die Fettspaltung ist um so grösser anzunehmen, wenn der Pankreassaft in Gegenwart von Galle auf die Fette zu wirken Gelegenheit hat. Ferner ist zu berücksichtigen, dass im Darm nach allen Richtungen hin weit günstigere Bedingungen für die Spaltung vorhanden sind als in vitro. 
Es ist auch eine sehr wichtige Frage, wie weit die Fettspaltung im Dünndarm geht, welcher Unterschied zwischen der Fettspaltung im oberen Dünndarm und derjenigen im unteren Dünndarm" besteht und welché Menge der gespaltenen Fettsäure in Seife übergeht.

Ich habe jeden Inhalt zuerst" direkt mit Äther extrahiert und die Menge des Ätherextraktes bestimmt; dann habe ich denselben mit $\mathrm{H}_{2} \mathrm{SO}_{4}$ stark angesäuert, mit Äther die freigemachte Fettsäure extrahiert und deren Menge bestimmt. Die freie Fettsäure: ist stets als Oleinsäure berechnet worden. 


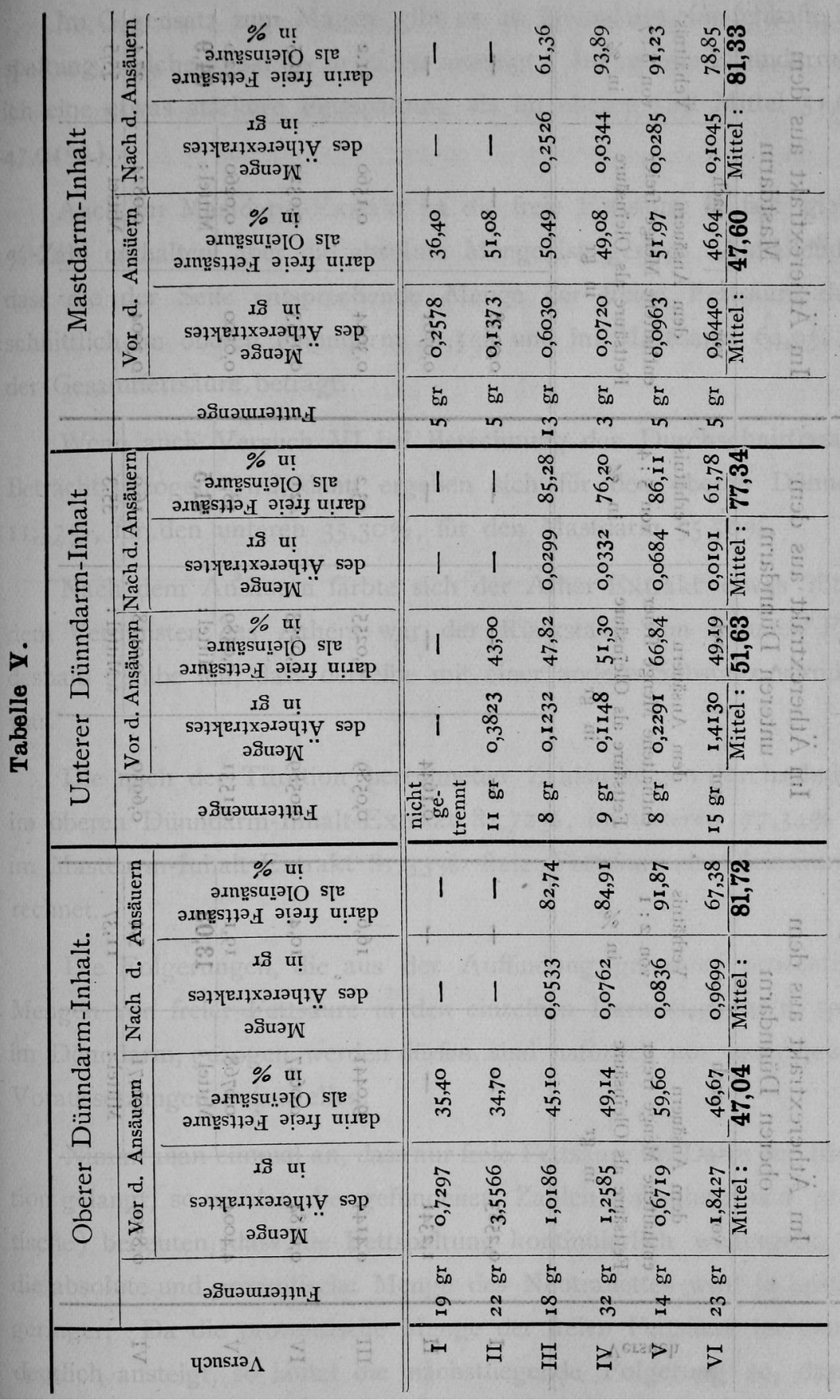




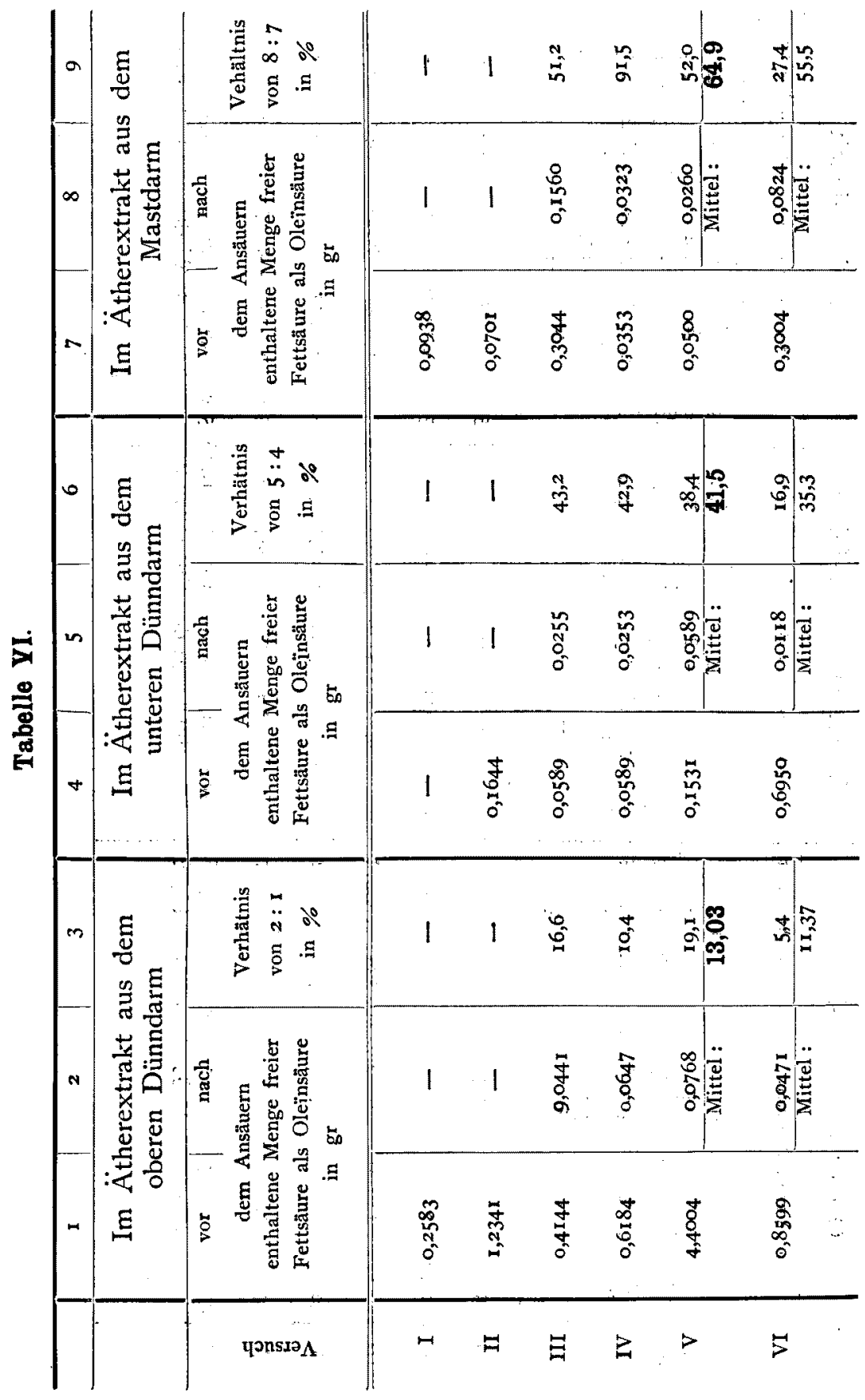


Im Gegensatz zum Magen gibt es im Dünndarm eine lebhafte Fettspaltung, welche selbst bis zu 66,8\% ansteigt. Im unteren Dünndarm fand ich eine etwas stärkere Fettspaltung als im oberen (im Mittel 51,6\%: $47,04 \% 6)$.

Auch im Mastdarm-Extrakt ist die freie Fettsäure in fast gleicher \%6-Zahl enthalten, aber die absolute Menge ist gering. Auffallend ist, dass die der Seife entsprechende Menge der freien Fettsäure durchschnittlich im oberen Dünndarm $41,5 \%$ und im Mastdarm 64,9\% von der Gesamtfettsäure beträgt.

Wenn auch Versuch VI bei Berechnung der Durchschnittrszahl in Betracht gezogen wird, dann ergeben sich für den oberen Dünndarm II,37\%, für den unteren 35,30\%, für den Mastdarm 55,50\%.

Nach dem Ansäuern färbte sich der Äther-Extrakt etwas rötlich; dem Verdunsten des Äthers war der Rückstand von brauner Farbe, deshalb glaube ich, dass derselbe mit einer andern Substanz vermischt, war.

Die nach der Titration berechneten Zahlen zeigen durchschnittlich im oberen Dünndarm-Inhalt-Extrakt $81,72 \%$, im unteren $77,34 \%$ und im Mastdarm-Inhalt-Extrakt $81,33 \%$ freie Fettsäure als Oleinsäure berechnet.

Die Folgerungen, die aus der Auffindung grösserer prozentischer Mengen von freier Fettsäure in den einzelnen Darmabschnitten, speziell im Dünndarm, gezogen werden dürfen, sind natürlich nur unter gewissen Voraussetzungen aufzustellen.

Nimmt man eimmal an, dass nur freie Fettsäure im Darm zur Resorption gelangt, so würden die gefundenen Zahlen (absolute und prozentische) bedeuten, dass die Fettspaltung kontinuierlich weitergeht, denn die absolute und prozentische Menge des Neutralfettes wird ja beständig geringer. Da die prozentische Menge der freien Fettsäure im Darm so deutlich ansteigt, so lautet die nächstliegende Folgerung so, dass die 
Fettspaltung schneller geschieht als die Resorption der freien Fettsäure. Gewiss sind auch andere Hypothesen möglich und sie liegen sehr nahe! Es soll hier nur das hervorgehoben werden, was für die Fettspaltung spricht und für diese sprechen die geschilderten Versuche sehr cieutlich.

Die fein geschnittene Dünndarm-Wand, deren Inhalt mit Filterpapier sorgfältig abgewischt und deren 'subperitoneales Fettgewebe sorgfaltig wegpräpariert war, wurde zuerst in Alkohol aufbewahrt, dann wurde der Alkohol auf dem Wasserbad eingedampt und die Wand getrocknet, mit Soxhlet'schem Apparat extrahiert und die Menge des Ätherextraktes' bestimmt. Darauf habe ich nochmals den Extrakt in Äther gelöst und mit alkoh. KOH-Lösung titriert, um den Säuregrad zu bestimmen.

Tabelle YII.

\begin{tabular}{|c|c|c|c|c|c|c|c|c|}
\hline & \multicolumn{4}{|c|}{ Obere Hälfte des Dünndarms } & \multicolumn{4}{|c|}{ Untere Hälfte des Dünndarms } \\
\hline $\begin{array}{l}\frac{5}{8} \\
\frac{3}{0} \\
?\end{array}$ & 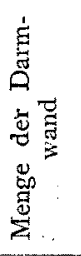 & 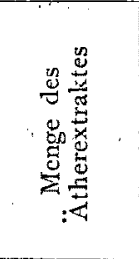 & 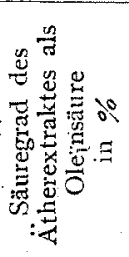 & 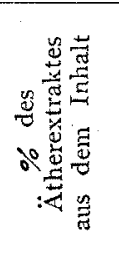 & 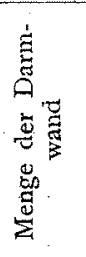 & 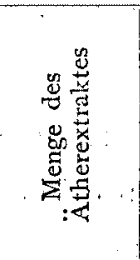 & 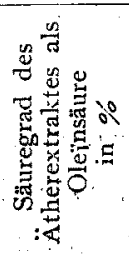 & 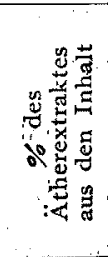 \\
\hline I & - & - & - & - & - & - & - & - \\
\hline II & $89 \mathrm{gr}$ & $\begin{array}{l}0,9080 \mathrm{gr} \\
(\mathrm{I}, 02 \%)\end{array}$ & 17,72 & $34,70 \%$ & $34 \mathrm{gr}$ & $\begin{array}{c}5,4 \text { or } 2 \mathrm{gr} \\
(\mathrm{I}, 88 \%)\end{array}$ & I8,32 & $43,00 \%$ \\
\hline III & $38 \mathrm{gr}$ & $\begin{array}{l}0,9727 \mathrm{gr} \\
(2,56 \%)\end{array}$ & 32,69 & $45,10 \%$ & $28 \mathrm{gr}$ & $\begin{array}{l}0,7655 \mathrm{gr} \\
(2,73 \%)\end{array}$ & 26,16 & $47,82 \%$ \\
\hline IV & $63 \mathrm{gr}$ & $\begin{array}{l}2,2923 \mathrm{gr} \\
(3,63 \%)\end{array}$ & 24,40 & $49,14 \%$ & $34 \mathrm{gr}$ & $\begin{array}{l}1,1135 \mathrm{gr} \\
(3,28 \%)\end{array}$ & $\begin{array}{c}37,02 \\
\ldots\end{array}$ & $51,30 \%$ \\
\hline $\mathrm{V}$ & $4 \circ \mathrm{gr}$ & $\begin{array}{l}1,0608 \mathrm{gr} \\
(2,65 \%)\end{array}$ & 33,31 & $59,60 \%$ & $29 \mathrm{gr}$ & $\begin{array}{l}0,556 \mathrm{r} \mathrm{gr} \\
(1,92 \%)\end{array}$ & $3 \mathrm{r}, 77$ & $66,84 \%$ \\
\hline VI & $37 \mathrm{gr}$ & $\begin{array}{l}0,9656 \mathrm{gr} \\
(2,6 \mathrm{I} \%)\end{array}$ & 20,13 & $46,67 \%$ & $28 \mathrm{gr}$ & $\begin{array}{l}0,5702 \mathrm{gr} \\
(2,04 \%)\end{array}$ & 28,92 & $49,19 \%$ \\
\hline & & Mittel: & 25,65 & & & Mttel : & 28,43 & \\
\hline
\end{tabular}


Die Dünndarm-Wand enthält durchschnittlich $2,5 \%$ Ätherextrakt. Dieser enthält in der oberen Hälfte $25,65 \%$, in der unteren Hälfte $28,43 \%$ freie Säure. Merkwürdig ist, dass der Ätherextrakt aus der. Darmwand relativ viel freie Fettsäure enthält, mehr als die Hälfte des Ätherextraktes aus dem Dünndarm-Inhalt, obwohl von letzterem, welcher freie Fettsäure in hohem Grade enthält; an der Darmwand nur ein wenig haften geblieben war. Deshalb glaube ich sagen zu dürfen, dass eine ziemlich grosse Menge abgespaltenen freien Fettsäure direkt in Form von Fettsäure von der Dünndarm-Wand" resorbiert und diese in der Wand nicht sofort in Neutralfett úmgewandelt werde.

Ferner habe ich die aus dem Darminhalt mit Äther ausgegeschüttelten Extrakte analysiert, um zu prüfen, ob die ganze Menge derselben nur aus Fett und Fettsäure bestehe. Als Kontrolle habe ich zuerst die gesammte Menge der Fettsäure des Schweinefettes bestimnt. Ich habe eine bestimmte Menge gewogen, mit einer gewissen Menge von $\mathrm{KOH}$ Lösung von bestimmtem Gehalt versetzt, auf dem Wasserbad über eine Stunde lang mit dem Rückflusskühler gekocht, daǹn. nach dem Kühlen mit HCl-Lösung von bskanntem Gehalt zurücktitriert. · Dann habe ich die alkoholische Lösung weiter behandelt, indem, jch den Alkohol eindampfte, die Lösung in den Scheidetrichter brachte, mit Salzsäure stark ansäuerte und mit Äther nochmals extrahierte.

1." "Die ätherische Lösủng wurde mit Wasser gewaschen und mit $\mathrm{KOH}$ titriert. ' Zur Kontrolle wurde zuerst eine abgewogene getrocknete Menge Schweinefett auf diese Weise behandelt.

$\because \quad$ Wenn man Schweinefett als Neutralfett der Oleinsäure bstrachtet, kann man nach den untenstehenden Formeln aus der Verseifungszahl die Fettsäure berechnen.

zum Verseifen :

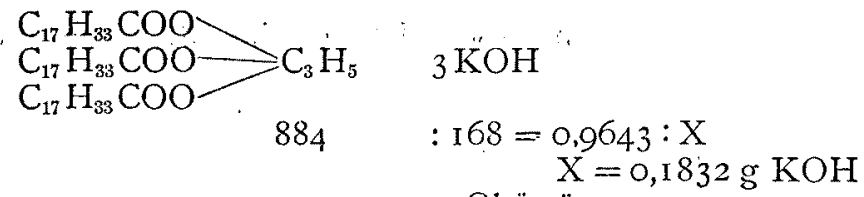

Neutralölfett

3 Oleïnsäure $\mathrm{X}=0, \mathrm{I} 832 \mathrm{~g} \mathrm{KOH}$

884

$$
\begin{array}{ll}
: 846 & =100: \mathrm{X} \\
\mathrm{X} & =95,7 \% .
\end{array}
$$




\section{Analyse I.}

Das Schweinefett enthält $0,66 \%$ freie Säure (als Oleinsäure bestimmt).

Abgewogenes Schweinefett 0,9643 gr.

Die zum Verseifen nötige Menge $\mathrm{KOH}-\mathrm{Lösung}$ betrug $8,3 \mathrm{~cm}^{3}$, welche 0,1942 gr $\mathrm{KOH}$ entsprechen.

Zum Neutralisieren der ätherischen Lösung, welche ich nach dem Ansäuern bekam, wandte ich $8,3 \mathrm{~cm}^{3} \mathrm{KOH}-L o ̈ s u n g$ an. Aus dieser Zahl habe ich IOI,39\% berechnet.

Analyse II.
Abgewogenes Schweinefett $0,7268 \mathrm{gr}$;
zum Verseifen $6,27 \mathrm{~cm}^{3} \mathrm{KOH}$-Lösung $=0,1467 \mathrm{gr} \mathrm{KOH}$, bei II. Titrierung angewandte $\mathrm{KOH}$ -

$$
\text { Lösung }=6, \text { I } 5 \mathrm{~cm}^{3}=0,1439 \mathrm{gr} \mathrm{KOH} \text {. }
$$

Aus dieser Zahl berechnete ich $\%=99,67$.

Das Schweinefett enthält aber nicht nur. Oleïnsäure, sondern auch Palmitin- und Stearinsäure. Deshalb ist es selbstverständlich, dass die Zahl, welche unter der Annahme, Schweinefett bestehe nur aus Olèinsäure, gefunden wurde, nicht genau stimmt. Jedenfalls geht aus der Übereinstimmung der bei der I. und II. Titrierung gefundenen Zahlen hervor, dass die Methode brauchbare Resultate liefert:

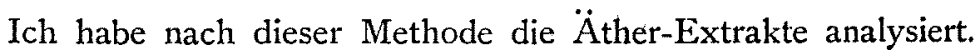




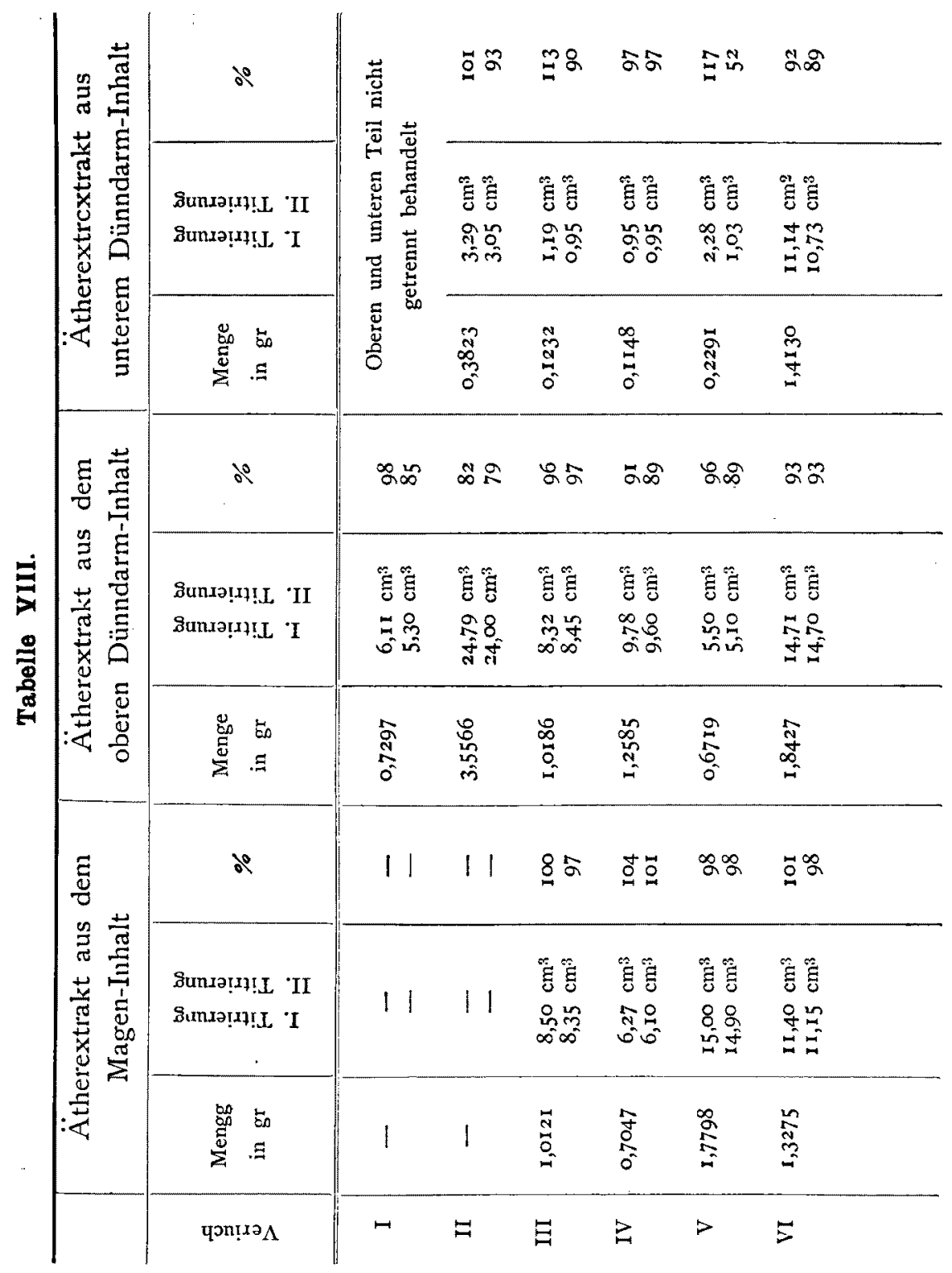


Die Zahlen in der Tabelle stehen den Zahlen aus der Berechnung nach der chemischen Formel wahe und die beiden Zahlen, welche die Menge der KOH-Lösung bei der I. Titrierung und jene bei der II. Titrierung angeben, sind fast gleich, ausser bei dem Äther-Extrakt aus idem unteren Dünndarmwand-Inhalte bei Versuch V. Deshalb glaube ich sagen zu können, dass die Äther-Extrakte, welche ich aus den Inhalten bekam, nur aus Neutralfett und Fettsäure bestanden und die Säuregrade, welche ich gefunden habe, nur durch die freje Fettsäure verursacht sind.

Die Äther-Extrakte, welche ich aus den Dünndarm-Inhalten nach dem Ansäuern und aus den Mastdarm-Inhalten bekam, konnte ich nicht analysieren, weil die Menge sehr gering war.

Bei den vorher geschilderten Versuchen habe ich den Fettgehalt der Dünndarm-Wand und die freie Säuremenge des extrahierten Fettes bestimmt. Um den Fettgehalt der Schleimhaut, sowie den Säuregrad unter denselben Verhältnissen getrennt prüfen zu können, stellte ich noç zwei weitere Tierversuche an; gleichzeitig habe ich auch Magen- und Darminhalt untersucht.

Tierversuche.

\section{Versuch VII und VIII.}

Am 20. Juni um I $2^{\text {h }}$ bekam jeder der beiden Hunde folgendes Futter :

$300 \mathrm{gr}$ Fleisch,

60 gr Fettmischung (9,88\% ige freie Säure).

Diese Fütterung wurde bis zum 24 . Juni $4 \mathrm{mal}$ wiederholt. $5 \frac{1}{2}$ Stunden nach der letzten Fütterung tötete ich einen Hund von $6,3 \mathrm{~kg}$ Körpergevicht.

Die Tötung des anderen Hundes in Körpergewicht von 7, $\mathrm{kg}$ erfolgte $7^{1 / 2}$ Stunden nach der letzten Fütterung.

Magen- und Dünndarm-Inhalt wurden ganz genau wie bei den beschriebenen Versuchen gesammelt und untersucht. Die Resultate dieser Untersuchungen sind aus den Tabellen IX, X und XI ersichtlich. 


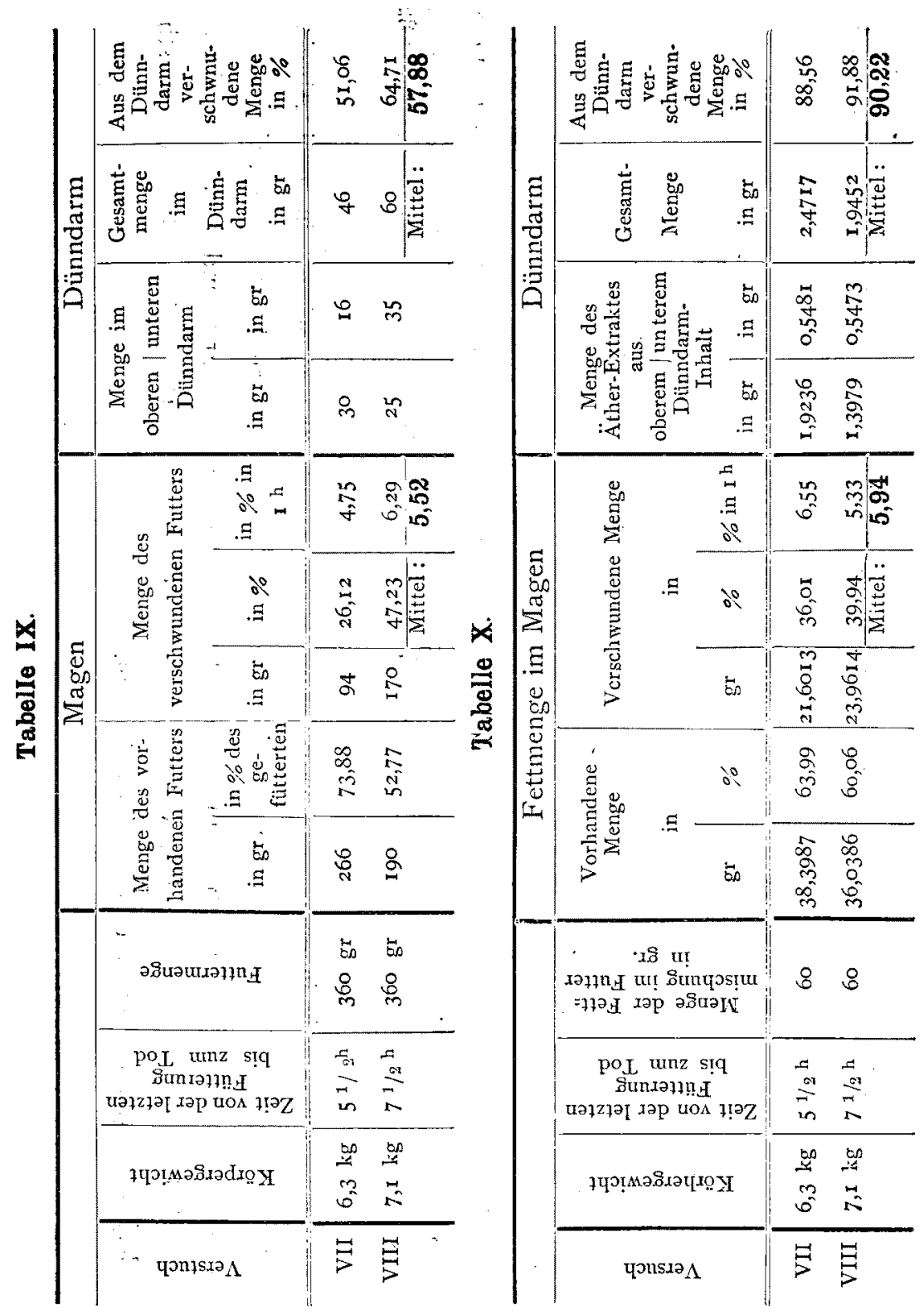




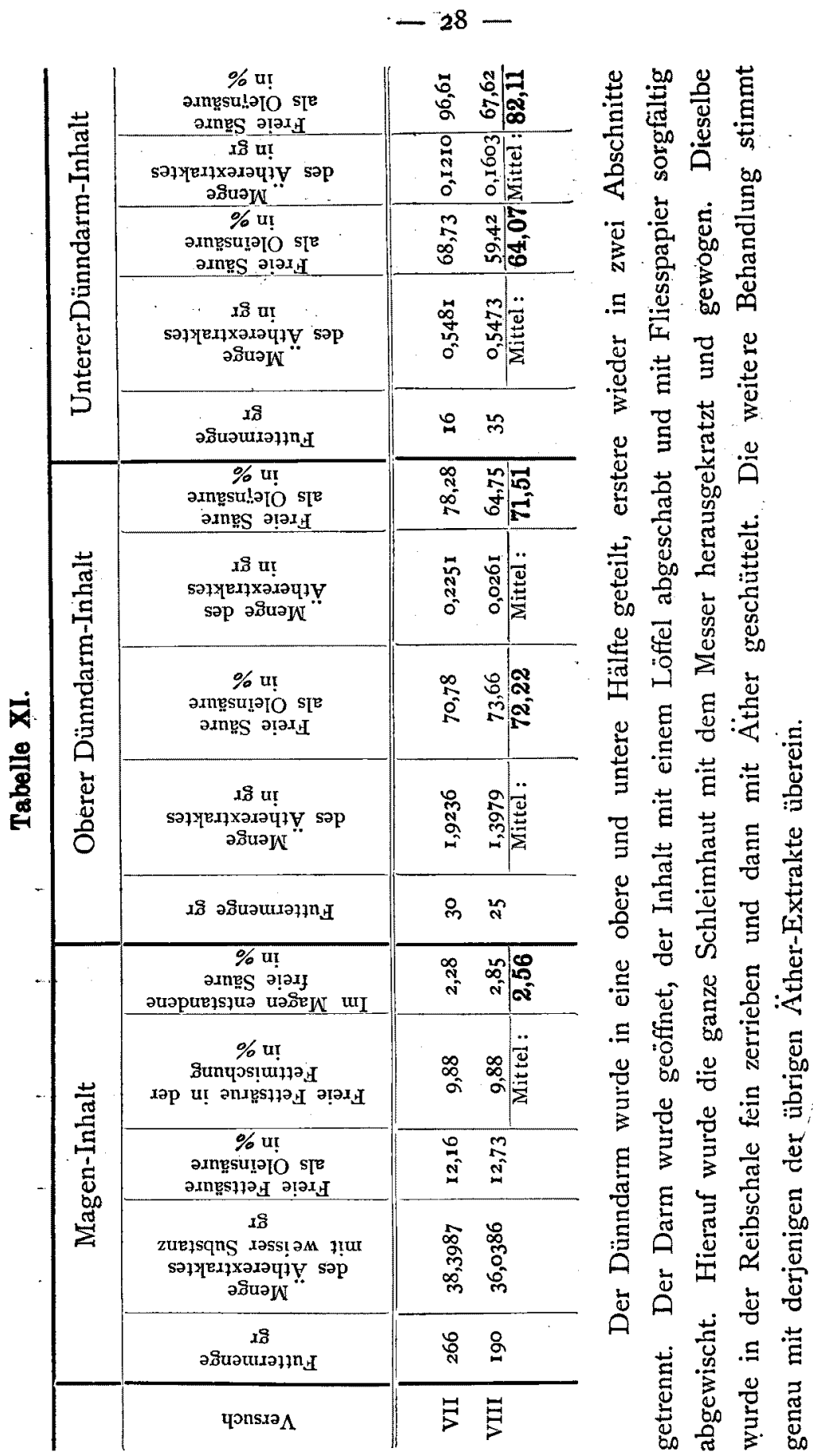




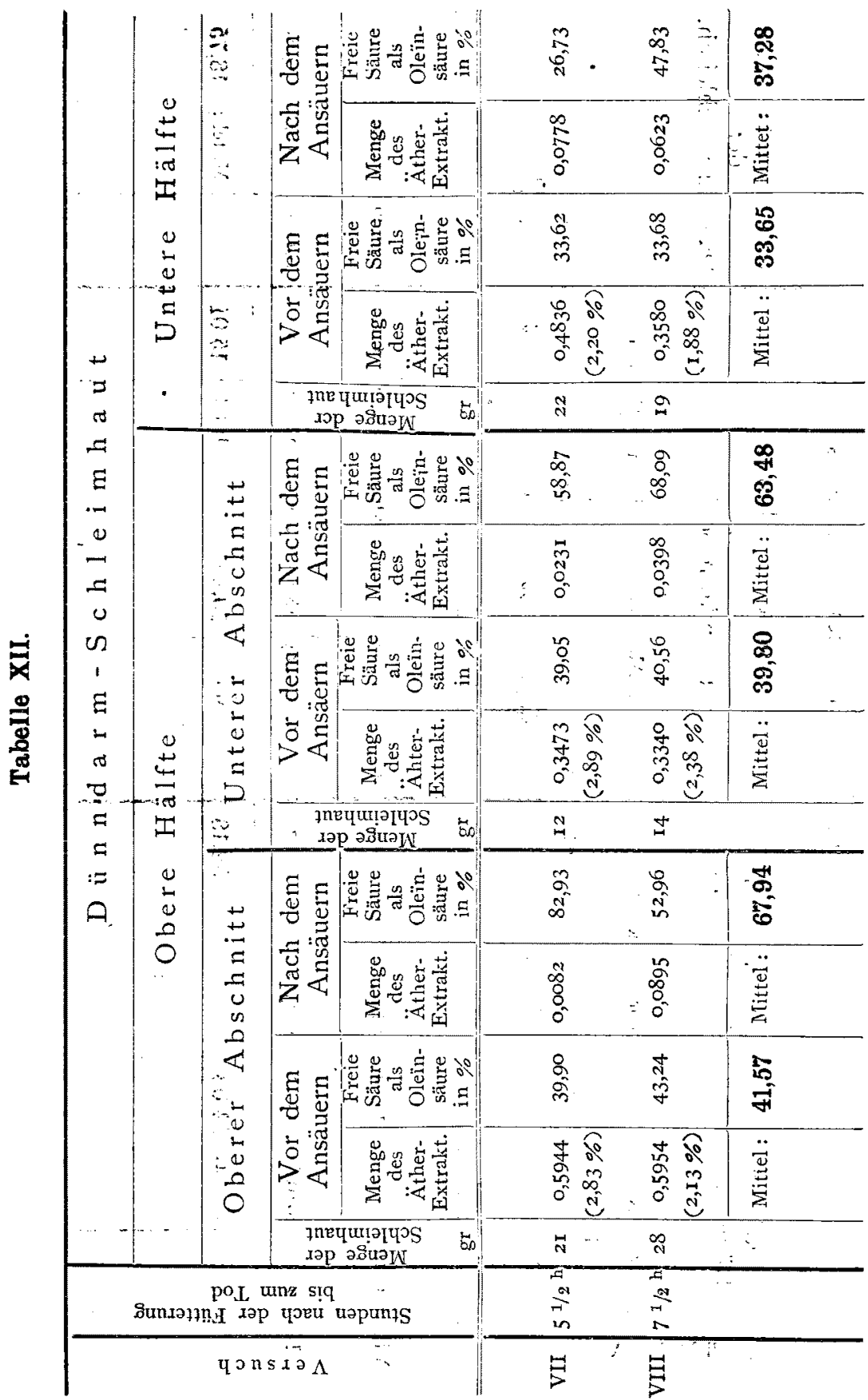




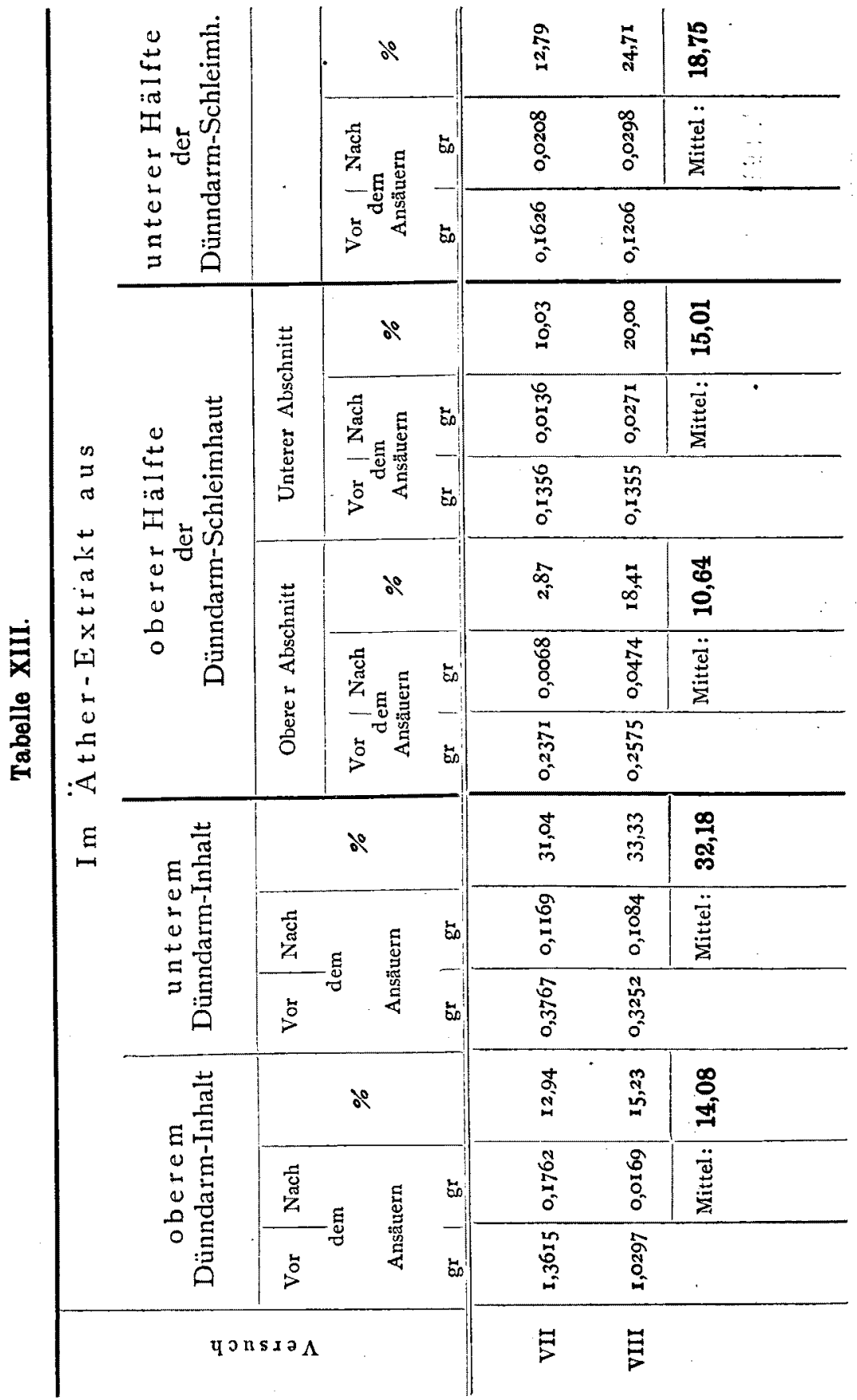


Die Schleimhaut des Dünndarms gab bei beiden Versuchen etwas mehr als 2\% Äther-Extrakt; der Säuregrad desselben war ziemlich hoch. Er betrug beim $\ddot{A}$ ther-Extrakt der oberen Hälfte 39,80-4I,57\%, bei der unteren dagegen nur $33,65 \%$, also ungefähr $7 \%$ weniger. Zwischen dem Säuregrad des Äther-Extraktes aus dem oberen und demjenigen aus dem unteren Abschnitt der oberen Hälfte (4I,57\% und 39,80\%) ist kein grosser Unterschied zu finden.

Von oben nach unten nimmt der Säuregrad allmählich ab. Beim Vèrgleich der Säuregrade der Schleimhaut-Extrakte mit denjenigen der Inhalt-Extrakte fand ich, dass erstere an Menge der freien Fettsäure mehr als die Hälfte der Säuregrade der letzteren enthalten. Ich will hier, was

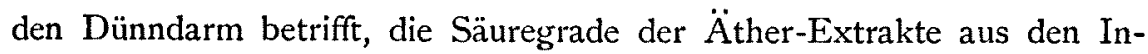
halten; jene der Darmwände mit Schleimhaut (Tab. VII) und jene der Schleimhäute allein (Tab. XII) tabellarisch zusammenstellen.

\section{Tabelle XIY.}

\begin{tabular}{|c|c|c|c|c|c|c|c|}
\hline \multirow{3}{*}{ 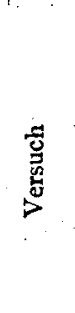 } & \multicolumn{7}{|c|}{ Freje Fettsäure als Oleïnsäure in $\%$. } \\
\hline & \multicolumn{4}{|c|}{ Obere Hälfte des Dünndarmes } & \multicolumn{3}{|c|}{$\begin{array}{l}\text { Untere Hälfte des } \\
\text { Düm Dunndarm }\end{array}$} \\
\hline & Inhalt & $\begin{array}{c}\text { Wand } \\
\text { mit } \\
\text { Schleim- } \\
\text { haut }\end{array}$ & $\begin{array}{r}\text { Schle } \\
\text { al }\end{array}$ & $\begin{array}{l}\text { haut } \\
\mathrm{m}\end{array}$ & Inhalt & $\begin{array}{l}\text { Wand } \\
\text { mit } \\
\text { Schleim- } \\
\text { haut }\end{array}$ & $\begin{array}{l}\text { Schleim- } \\
\text { haut } \\
\text { allein }\end{array}$ \\
\hline I & - & - & & & - & - & - \\
\hline II & 34,70 & 17,72 & & & 43,00 & 18,32 & - \\
\hline III & 45,10 & 32,69 & & & 47,82 & 26,16 & - \\
\hline IV & 49,14 & 24,40 & & & $51,3^{\circ}$. & 37,02 & - \\
\hline $\mathrm{V}$ & 59,60 & $33,3^{1}$ & & & 66,84 & $3 \mathbf{1}, 77$ & - \\
\hline VI & 46,67 & 20,13 & $\begin{array}{l}\text { Oberer } \\
\text { Abs }\end{array}$ & $\begin{array}{l}\text { Unterer } \\
\text { nitt }\end{array}$ & 49,19 & 28,92 & - \\
\hline VII & 70,78 & - & 39,90 & 39,05 & 68,73 & $\rightarrow$ & 33,62 \\
\hline VIII & 73,66 & - & 43,24 & 40,56 & 59,42 & - & 33,68 \\
\hline
\end{tabular}


In der Tabelle XIV sind die Zahlen angeggebèn, welche die im $\ddot{A}$ therExtrakt aus dem Darminhalt und der Darm-Schleimhaut vor und nach dem Ansäuern vorhandene Fettsäure-Menge in Prozenten zeigen: Die der Seife entsprechende Menge freier Fettsäure der Schleimhant ist lzkeiner als jene des Inhaltes. Von oben nach unten nimmt die Menge allnählich $\mathrm{zn}$.

Zum Schluss fasse ich aus meiner Arbeit folgendes zusammen:

I. Bei mässiger Enährung kleinerer Hunde gehen ungefähr 5,94$6,02 \%$ des Futters (Tab. X und I) pro Stunde aus dem. Magen in den Dünndarm über und sind in $6-7 \%$ Stunden $50,04 \pi$ $57,88 \%$ (Tab. IX und I). des Futters aus dem Dünndarm verschwunden.

2. Bei Ernährung nicht grosser Hunde mit einem Futter, das $20 \%$ Fettmischung (10\%:ige Oleinsäure enthaltendes Schweineschmala) enthält, gehen pro Stunde 5,94 bis $8,39 \%$ der Fettmischung aus dem Magen in den Dünndarm über und sind in $6-7 \%$ 90,22 bis 93,50\% (Tab. X und $\mathrm{H}$ ) der-Fettmischung aus dem Dünndarm verschwunden.

3. Im Magen findet kene lebhafte Fettspaltung statt. Bei $6-7^{1 / 2}$ stündigem Verweilen des Fettes im Magen nimmt die freie Fettsäure nur un $1,63-2,56 \%$ zu (Tab. IV und XI). Es ist mir nicht möglich, die Ursache davon zu erklären.

4. Im Dünndarm dagegen findet eine lebhafte Fettspaltung statt; in der oberen Hälfte des Dünndarms steigt die freie Fetțäure auf 47,04-72,22\% (davon müssen 10\% freie Säure, die im Futter enthalten waren, subtrahiert werden), in der unteren Hälfte auf $51,63-64,07 \%$ (Tab. V und XI).

5. Im Mastdarm beträgt die Fettsäure im Mittel 47,6\% (Tap. V).

6. Im oberen Dünndarm beträgt die der Seife entsprechendẹ freie Fettsäure 13,30\%, im unteren Dünndarm 4I,50\%, in: Maștdarm $64,90 \%$ (Tab. VI). 


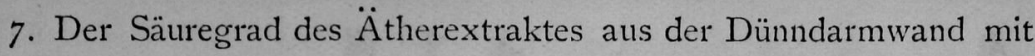
Schleimhaut, sowie derjenige der Dünndarm-Schleimhaut allein beträgt mehr als die Hälfte von demjenigen des Äther-Extraktes

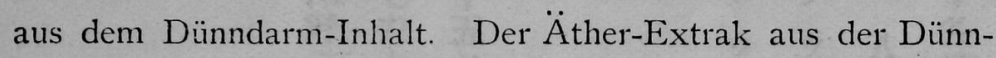
darm-Schleimhaut enthält etwaș mehr freie Säure als derjenige aus der Dünndarmwand mit Schleimhaut (Tab- VII, XII, XIV).

8. Aus diesem Grunde glaube ich sagen zu dürfen, dass eine ziemlich grossn Menge gespaltener freier Fettsaure direkt in Form von Fettsäure von der Darmwand resorbiert wird.

9. Da die Prozentische Menge der freien Fettsäure im Dünndarm deutlich ansteigt, so lautet die nächstliegende Folgerung, dass die Fettspaltung schneller geschieht, als die Resorption der

freien Fettsäure.

S.

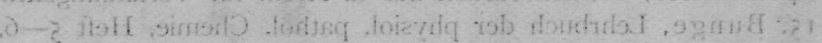

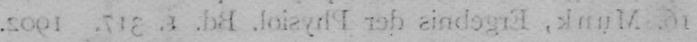

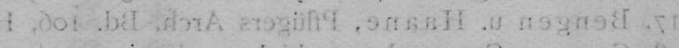

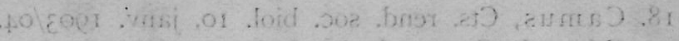

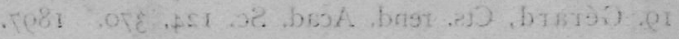

74um Schlusse sei es mir gestattet, dem Andenken meines so unerwartet dahingeschiedeneri hochverehrten Lehrers, Professor K un kel, meine Dankesschuld abzutragen.

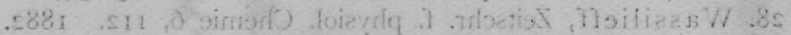




\section{Literatur.}

I. Volhard, F., Zeitschr. f. klin. Med. 42, Heft 5-6, r9or.

2. Frank, Otto, Archiv f, Anat. und Physiol. Separat-Abzug S. 5or.

3. Munk, J., Virchows Archiv, 95, 452. 1884.

4. Müller, Fr., Zeitschr. für klin. Med. 12-45. 1887:

5. Arnschink, Zeitschrift f. Biologie 26, 433. I 890 .

6. Marpmann, Münch. med. Wochenschr. 485. 1888.

7. Marcet, The med. Times and Gazette 17, 2 10. 1858.

8. Cash, Archiv f. Physiologie 323. 1880.

9. Ogata, Archiv für Physiologie 515. I88I.

Io. Klemperer u. Scheurlen, Zeitschr. f. klin. Med. I5, 370. I889.

Ir. Müller, Zeitschr. f. klin. Med. r2. S. ro7.

12. Stade, Hofmeisters Beitr. zur Chemie, Phys. u. Pathol. 3, 291.

13. Inouye, Sonderabdruck aus d. Arch. für Verdauungskrankh. S. 251-262.

14. Kunkel, Sonderabdruck aus d. Arch. für Verdauungskrankh. S. 251-262.

I5. Bunge, Lehrbuch der physiol. pathol. Chemie, Heft 5-6.

16. Munk, Ergebnis der Physiol. Bd. 1. 317. 1902.

I7. Bengen u. Haane, Pflügers Arch. Bd. 106, H. 6/7.

I8. Camus, Cts. rend. soc. biol. 10, janv. 1903/04.

I9. Gérard, Cts. rend. Acad. Sc. I24, 370. 1897.

20. Laxa, Arch. f. Hyg. 4r, I19. $190 \mathrm{I}$.

21. Biffen, Annals of Botany 13. 363. I899.

22. Krüger u. Schreiber, Arch. f. Hyg. 41, 328. 190 I.

23. Rubner, Arch. f. Hyg. 38, 67. 1900.

24. v. Sommaruga, Zeitschr. f. Hyg. I8, 44I.

25. Escherich, Die Darmbakterien des Säuglings. ' 1886.

26. Herter, Zeitschr. f. physiol. Chemie 4, 160. 1880 .

27. Lüdy, Arch. f. experim. Path. u. Pharmak. 25, 347. 1889.

28. Wassilieff, Zeitschr. f. physiol. Chemie 6, I12. 1882.

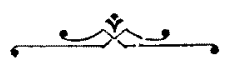

